\title{
Yüksek mahkeme kararlarında serebral palsi olguları
}

\section{Cerebral palsy cases in supreme court decisions}

\author{
Serdar Şirazi ${ }^{1}$, İlhan Açıkgöz², Semra Esenkaya ${ }^{3}$ \\ 10rtopedi ve Travmatoloji Uzmanı - Hukukçu - Arabulucu; Özel Avcılar Anadolu Hastanesi - Şahin Avukatlık Bürosu - \\ Akademi Arabuluculuk ve Tahkim Merkezi, İstanbul \\ ${ }^{2}$ istanbul Barosu Avukatı - Ortopedi ve Travmatoloji Uzmanı - Hastane ve Sağlık İşletmeleri Yöneticisi - Doktor Avukat - \\ Sağlık Hukuku Uzmanı, İstanbul \\ ${ }^{3}$ Kadın Hastalıkları ve Doğum Uzmanı, VM Medical Park Pendik Hastanesi, İstanbul
}

Ortopedi ve travmatoloji branşında önemli bir yer teşkil eden serebral palsi hastaları cerrahi müdahalelerden sonra rehabilitasyon görmeleri ve daha sonraki dönemlerde farklı cerrahilere ihtiyaç duyabilmeleri nedeniyle uzun yıllar takipte kalmakta ve uzun süreli hasta hekim ilişkisinin iyi bir örneğini oluşturmaktadırlar. Multidisipliner bir yaklaşım gerektiren serebral palsi olguları ile ilgili medikolegal sorunlar, kadın hastalıkları ve doğum hekimleri yönünden doğum esnasında oluşan komplikasyonlarla ilgili olabileceği gibi, ortopedi ve travmatoloji hekimleri yönünden de deformite düzeltme ameliyatları sonrası karşılaşılan sorunlar olarak karşımıza çıkabilmektedir. Makalemizde, yüksek mahkeme kararlarında serebral palsi olguları incelenmiş ve örnek teşkil etme potansiyeline sahip olgulara yer verilmiştir. Ortopedi ve travmatoloji hekimleri ile olan uyuşmazlıkların çok sık olmamasında, hekim ile hasta ve hasta yakını arasındaki iletişimin güçlü olması da etken olarak düşünülebilecektir.

Anahtar sözcükler: serebral palsi; komplikasyon; malpraktis; sağlık hukuku; tıp hukuku
Cerebral palsy patients constitute an important place in orthopedics and traumatology, especially in the field of pediatric orthopedics, with a long-lasting follow-up period in the outpatient clinic for many years due to need for rehabilitation after surgical intervention and prospective surgical procedures. In this respect, they can be considered as pivotal examples of a long-term patient-physician relationship. Medicolegal problems related to cerebral palsy cases requiring a multidisciplinary approach may be due to complications of obstetrics and gynecology during delivery as well as orthopedics and traumatology as a result of or after deformity correction surgeries. In our article, cases of cerebral palsy were examined in high court decisions and cases with the potential to set an example are included. The strong communication between the physician, the patient and the patient's relatives can be considered as a factor in the fact that the conflicts with orthopedics and traumatology surgeons are not very frequent.

Key words: cerebral palsy; complication; malpractice; health law; medical law

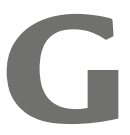
elişmekte olan merkezi sinir sisteminin hasarına bağlı ortaya çıkan motor işlev bozukluğu olan serebral palsi (SP) tanılı hastalar farklı şikayet ve klinik bulgularla ortopedi ve travmatoloji hekimine her yaşta başvurabilmektedir. Motor fonksiyon bozukluğu, ilerleyen süreçte kas-iskelet sisteminde de araza neden olmakta, ortopedi ve travmatoloji hekiminin müdahale etmesi gereken seviyeye gelebilmektedir. Bu yönüyle multidisipliner bir yaklaşım gerektiren serebral palsi, ortopedi ve travmatoloji, fizik tedavi ve rehabilitasyon, nöroloji, nöröşirürji ve çocuk hastalıkları hekimlerinin birlikte değerlendirip tanısını koyduğu, tedavisini yürüttüğü ve takip ettiği bir hastalık konumundadır. Bu branşlara ilaveten serebral palsi olguları kadın hastalıkları ve doğum hekimlerinin de doğum esnasında oluşan komplikasyonlar nedeniyle karşılaşabilecekleri bir durumdur. Öyle ki, medikolegal açıdan bu konuda yargıya yansıyan olguların büyük bir kısmı kadın hastalıkları ve doğum hekiminin müdahil olduğu davalardır.

- Illetişim adresi: Dr. Serdar Şirazi, Akademi Arabuluculuk ve Tahkim Merkezi. Ofis: Florya Plaza, Şenlikköy Mah. Eski Halkalı Cad. No: 3, K: 2, D: 25B. Florya, Bakırköy, İstanbul Tel: 0536 - 6811187 e-posta: drserdarsirazi@yahoo.com 
Tıpta Uzmanlık Kurulu Müfredat Oluşturma ve Standart Belirleme Sisteminde (TUKMOS) yer alan ortopedi ve travmatoloji uzmanlık eğitimi çekirdek müfredatında nörömusküler hastalıklar grubunda yer alan serebral palsi hastalığının ekip çalışmasının gerektirdiği durumlar dışında herhangi bir desteğe gereksinim duymadan hastanın tanı ve tedavisinin tüm sürecini yönetebilmesi gerektiği vurgulanmıştır.[1] Dolayısıyla serebral palsi hastaları gerek uzmanlık eğitiminde gerekse uzmanlık döneminde ortopedi ve travmatoloji hekiminin uğraş alanı içine oldukça sık bir şekilde girmektedir.

Ortopedi ve travmatoloji alanında özellikle çocuk ortopedisi branşında önemli bir yer teşkil eden serebral palsi olguları cerrahi müdahaleden sonra rehabilitasyon görmeleri, daha sonraki dönemlerde tekrar cerrahiye ihtiyaç duyabilmeleri, dolayısıyla poliklinikte uzun yıllar takipte kalmalarından ötürü oldukça uzun süreli bir hasta hekim ilişkisinin iyi örneklerinden sayılabilecektir. Zira yüksek mahkeme kararlarında ortopedi ve travmatoloji hekiminin taraf olduğu dava sayısı oldukça azdır. Bu konuda uyuşmazlıklarda ne yazık ki kadın hastalıkları ve doğum hekimleri daha sıklıkta yer almaktadır. Makalemizde yüksek mahkeme kararlarında serebral palsi olguları incelenmiş ve örnek teşkil etme potansiyeline sahip olgulara yer verilmiştir.

\section{Örnek Olgu 1}

ilk örnek olgu; serebral palsi tanısı olan, her iki kalça adduksiyon kısıtlılı̆̆ı ve kalça çıkığı bulunan çocuğun velisi hastanın bir ayağını diğer ayağının üzerinde tutma, ayakta dikilememe, yürüyememe ve oturamama şikayetleriyle başvurmuş ve ortopedi ve travmatoloji kliniğine yatışı yapılarak kalça çıkığı nedeniyle ameliyatı yapılmış. Yaklaşık 14 ay sonra implant çıkarma ameliyatı uygulanmış. Üç yıl sonra ranzadan düşme sonucu üniversite hastanesi ortopedi ve travmatoloji kliniğine başvurmuş ve tüm bu girişimlerden ötürü felç olduğu iddiasıyla dava açılmış. ${ }^{2]}$

Illk ameliyattan yaklaşık 12 yıl sonraki şikâyeti ile aile "oğlunun yürüyememe şikâyeti olduğunu, 2006 yılında şüpheli tarafindan ameliyat edildiğini, 2007 yılında bu ameliyat esnasında takılan demirlerin çıkarıldı̆̆ını, hastaneye geldiğinde çocuğunun yürüyemediğini, bir ayağını diğer ayă̆ııın üzerinde tuttuğunu, bu ameliyattan sonra çocuğunun 2-3 ay sonra yürüyeceğinin söylendiğini ancak ameliyat sonrası çocuğunun yürüyemediğini, çocuğunun tedavisinin yapılmasını ve ayağa kalkmasını talep ettiğini" ifade etmiştir. ${ }^{[2]}$

Danıştay Birinci Dairesi yerel mahkemenin hekim lehine verdiği kararı "davacının 6 aylık şikâyet süresi geçtikten sonra şikayetçi olunduğu, 23.6.2006 tarihli ve 17.8.2007 tarihli ameliyatlardan 2-3 ay sonra çocuğunun yürüyemediğini öğrenen şikayetçi tarafindan 6 ay içerisinde şikayette bulunulması gerekirken, şikayet süresi 11-12 yıl geçirildikten sonra 8.6.2018 tarihinde şikayette bulunuldu$\breve{g} u$, bu nedenle şüpheli hakkında ceza soruşturması yapılamayacağı ve kurul kararı alınamayacağına" karar vermiş. ${ }^{[2]}$

5237 sayılı Türk Ceza Kanunu'nun "Soruşturulması ve kovuşturulması şikâyete bağlı suçlar" başlıklı 73 . maddesinin birinci fikrasında; soruşturulması ve kovuşturulması şikâyete bağlı olan suç hakkında yetkili kimse altı ay içinde şikâyette bulunmadığı takdirde soruşturma ve kovuşturma yapılamayacă̆ı, ikinci fikrasında; zamanaşımı süresini geçmemek koşuluyla bu sürenin, şikâyet hakkı olan kişinin fiili ve failin kim olduğunu bildiği veya öğrendiği günden başlayacağı belirtilmiştir. ${ }^{[3]}$

Türk Ceza Kanunun "taksirle yaralama” başıkılı 89. maddesinin birinci fikrasında ise; taksirle başkasının vücuduna acı veren veya sağ/ığııın ya da algılama yeteneğinin bozulmasına neden olan kişinin, üç aydan bir yıla kadar hapis cezası ile cezalandırılacăğ, anılan maddenin son fikrasında ise, taksirle yaralama fiilinin bilinçli taksirle işlenmesi hariç olmak üzere suçun soruşturulmasının ve kovuşturulmasının şikâyete bağlı olduğu hüküm altına alınmıştır. ${ }^{[3]}$ Dolayısıyla söz konusu davada Danıştay bu sürelerin aşıldığı gerekçesiyle başvuruyu reddetmiştir.

Yine ortopedi ve travmatoloji hekiminin serebral palsili hastaya yapacağı cerrahi müdahalelerden önce hastaya ve/veya yakınlarına yapılacak müdahalenin içeriği ve olası sonuçları hakkında ayrıntılı bilgi vermesi tedavi sonrası ortaya çıkabilecek uyuşmazlıkların önüne geçilmesine neden olabilecektir. Keza bu konuda bilgilendirme ve iletişim, yapılacak müdahalenin hastadaki bütün problemleri ortadan kaldırmayacağını hasta ve velisinin bilmesi açısından önem arz etmektedir.

\section{Örnek Olgu 2}

Bir diğer karar Yargıtay 12. Ceza Dairesi tarafından 04.05.2016 tarihinde verilmiştir; spastik parapleji olan hastanın fizik tedavi ve rehabilitasyon hastanesinde fizyoterapistin uyguladığı egzersiz programında bastırma, çekme, germe ve uzatma hareketlerinde fazla bastırması iddiasıyla kemiklerinin osteoporotik olmasından dolayı sağ diz bölgesinde kırık meydana gelmesi ve fizyoterapist hakkında davacı olunmasını içermekte. Bu olayda, ilgili sağlık çalışanına, taksirle yaralama suçu atfedilerek ceza davası açılmıştır. ${ }^{[4]}$

Adli Tıp Kurumu tarafindan "femur ve tibiadaki kemik yapının ileri derecede osteoporotik olduğunun tespit edildiği, spastik parapleji hastasının fizik tedavi programı esnasında oluşan kemik kırıklarının germe işlemi sonrası her türlü özene rağmen görülebilecek komplikasyonlar arasında yer alması nedeniyle her türlü dikkat ve özene rağmen osteoporotik kırıklarda bu tarz komplikasyonların oluşabileceği”" 
raporlanmış. Yerel mahkeme tarafından yapılan yargılama sonunda, yüklenen suç açısından sağlık çalışanının taksirinin bulunmadığı gerekçeleri gösterilerek beraat kararı verilmiş. Davacılar tarafından karara itiraz edilmesi üzerine Yargıtay 12. Ceza Dairesi, yüklenen suç açısından sanı̆̆ın taksirinin bulunmadı̆̆ı gerekçelerini göstererek yerel mahkeme tarafindan verilen beraat kararını onamıştır. ${ }^{[4]}$

\section{Örnek Olgu 3}

Yargıtay 13. Hukuk Dairesi'nin verdiği bir kararda davacı, kadın hastalıkları ve doğum uzmanı tarafından doğum sırasında vakum kullanıldığını, çocuğun başının geldiğini ama omuzun gelmemesi üzerine tekrar kanala itilip sezaryen ile doğum yapıldığını, doktorun kusuru nedeniyle bebeğin \%100 engelli ve serebral palsi tanısı aldığı iddiasıyla dava açılmış. ${ }^{[5]}$

Adli Tıp Kurumu 3. İhtisas Kurulu'ndan alınan raporda "gebenin ıkınma zaafindan dolayı 2-3 kez vakum uygulandığı, doğumun gerçekleşmemesi ve çocuğun kalp seslerinin bozulması üzerine acil sezaryene alındığı, solunumu olmayan 2660 gr ağırlığında canlı bir bebek doğurtulduğu, doğan bebekte asfiktik doğum ön tanısı konulması üzerine hastaneye sevk edildiği, merkezde HiE (hipoksik iskemik ensefalopati) tanısı ile tedavi yapıldığı, mevcut tıbbi belgelere göre normal doğum kararının doğru olduğu, doğum eyleminde rahim ă̆zı açık iken gebenin ıkınma zaafina da vakum takılmasının uygun olduğu, vakuma rağmen doğumun gerçekleşmemesi üzerine fetal distres tanısı ile sezaryene alınmasının doğru olduğu, travaydaki (doğum eylemindeki) tıbbi belgelere göre travayda gebenin yakından takip edildiğinin anlaşıldığı, kollum tam açık oluncaya kadar çocuk kalp sesinde bir düşüş tespit edilmediği, genel uygulamalarda doğum öncesi, doğumda ve doğum sonrası olarak incelendiği, çocuk kalp sesinde meydana gelen bozulmaların bebekte gelişmiş olan asfiksinin en geç döneminde ortaya çıkan bulgular olduğu" belirtilmiş. Ayrıca "daha erken dönemde bebekte mevcut hipoksiyi tespit edebilecek herhangi bir klinik, laboratuvar veya teknolojik yöntem mevcut olmadığı, serebral palsi hastalığının nedeni tam olarak belli olmamakla birlikte daha ziyade perinatal asfiksiye bağlı olabileceği, bu asfiksinin tespit edilemeyeceği cihetle kadın hastalıkları ve doğum uzmanına kusur verilemeyeceği” mütalaa edilmiştir. ${ }^{[5]}$

Yerel mahkeme Adli Tıp Kurumu'nun bu raporunu dikkate alarak davanın reddine karar vermiş, karar davacılar tarafından temyiz edilmiştir.

Yargıtay, Adli Tıp Kurumu Raporu'nu “bebeğin serebral palsi olması ile doktorun eylemi arasında ilişki olup olmadığı hususuna açıklık getirmediğj” görüşü ile yetersiz bulmuştur. Yargitay 13. Hukuk Dairesi, “üniversitelerin kadın hastalıkları ve doğum anabilim dallarından seçilecek bir uzman bilirkişi heyeti tayin edilip dosyadaki hastanede tutulmuş dosya, kayıtlar, taraf savunmaları ve tüm delillerin birlikte değerlendirilerek, yapılması gerekenle yapılan müdahale ve tedavinin ne olduğu, tıbbın gerek ve kurallarına göre olayda doktor hatası olup olmadığını gösteren nedenlerini açıklayıcı, taraf, mahkeme ve Yargıtay denetimine elverişli rapor alınması ve bu şekilde ortaya çıkacak sonuca uygun karar verilmesi gerektiği”ne kanaat getirerek, hekim lehine verilen yerel mahkeme kararını bozmuştur. ${ }^{[5]}$ Bu şekilde dosya tekrar yerel mahkemeye gönderilerek Yargıtay'ın belirlediği kriterlerde yeni bir bilirkişi raporu alınarak yargılamanın tekrar yapılması kararı verilmiştir.

\section{Örnek Olgu 4}

Yargıtay 13. Hukuk Dairesi'nin verdiği kararda davacı "hamileliği boyunca davalı hastanede davalı doktorun kontrolünde bulunduğunu, 9.6.2005 tarihinde doğum sIvISI gelince davalılara müracaat ettiğini, nöbetçi doktor tarafindan muayene edildiğini, davalı doktorun talimatları doğrultusunda, sabaha kadar yatar pozisyonda bekletildiğini, ancak sabahında bebeğin kalp atışları alınamayınca acilen sezaryene alındığını, bu aşamada bebeğin kakasını yutması nedeni ile aspire edildiğini, ancak oksijensiz kaldığından yoğun bakıma alındığını ve 11 gün süre ile yoğun bakımda kaldığını" iddia etmiş, çekilen manyetik rezonans görüntüleme ile beyin felci teşhisi konulduğunu ileri sürerek, "davalıların zamanında doğum yaptırmayarak kusurlu olduklarını” ileri sürmüş, maddi ve manevi tazminata karar verilmesini istemiştir. ${ }^{[6]}$

Adli Tıp Kurumu 3. ihtisas Kurulu'nun 7.3.2008 tarihli raporu ile; "davacının 9.6.2005 tarihinde, miadında gebelik ve gebelik suyunun azalması nedeniyle davalı doktor tarafindan davalı hastaneye takip amacıyla yatırıldığı ve NST (non stres test) ile sürekli olarak takip edilerek kontrol altında tutulduğu, saat 22.40 ve 10.6.2005 günü saat 00.20'de NST'lerde 2 dakikalık deselerasyonlar olduğu, tekrarlayan deselarasyonlar olması nedeni ile kişinin sabaha kadar beklenmeden doğuma alınmasının uygun olacağı, devamında da saat 04.30'da 5 dakikadan uzun süren deselarasyona göre bu durumlardan haberdar olan doktorun eyleminin tip kurallarına uygun olmadı̆̆ı" açıklanmış, Adli Tıp Genel Kurulu da aynı yönde rapor vermiş ve ayrıca "bebeğin serebral palsi arızası nedeni ile \%100 meslekte kazanma güсünü kaybettiği ve sürekli bakım ve yardıma muhtaç durumda olduğunu" kaleme almıştır. Ancak davacıların bebeğinde teşhis edilen serebral palsi arızasının davalı eylemleri ile doğrudan bağlantılı olup olmadığı, doğumun gecikmesi nedeni ile oluşan hipoksinin bu arızaya neden olup olmadığı, açık ve ayrıntılı olarak belirtilmemiştir. Yargıtay 13. Hukuk Dairesi "bebekte teşhis edilen arıza ile davalıların eylemi arasındaki illiyet bağının varlı̆̆ı konusunda gerektiğinde ayrıntılı ek rapor alınarak açıklığa kavuşturulması gerektiği ve bunun sonucuna göre uygun bir karar verilmesi gerektiği" kanaatine vararak kararı bozmuştur. ${ }^{[6]}$ 
Kararda Yargıtay, bilirkişi olarakAdliTıp Kurumu'nun, raporunda, doktorun seçilen tedavi yöntemi ve tedavi aşamalarında gerekli titizliği gösterip göstermediğini, uygulanması gereken tedavinin ne olması gerektiğini, doktor tarafindan uygulanan tedavinin ne olduğunu, ayrıntılı ve gerekçeli açıklanması ve sonuca ulaşılması gerektiğine vurgu yapılmıştır. Yargıtay bu bağlamda raporda sadece yapılan işlemin ne olduğunu açıklamanın yeterli olmadığını belirtmiş, ayrıca tarafların itirazlarının da mutlaka karşılanması gerektiğini ve raporun aydınlatıcı özelliğe haiz olması gerektiğini vurgulamıştır. ${ }^{[6]}$

Somut olguda hastanın takibinde ortaya çıkan bir eksiklik olması nedeniyle Adli Tıp Kurumu müdahalenin geç yapıldığı kanaatine varmıştır. Bu kanaate dosya üzerindeki inceleme ile varılmış olması, hekimin kayıt tutma yükümlülüğünün önemine iyi bir örnek olarak karşımıza çıkmaktadır. Hasta ile ilgili bilgileri kayıt altına alma, hekimin yani hukuki nitelendirmeyle vekilin, özen yükümlülüğünün bir bileşenidir. Hastanın NST takiplerinin uygun yapılıp kayıt altına alınması durumunda benzer konularda uyuşmazlıkların önüne geçilmesi mümkün olabilecektir. Keza gereken tıbbi müdahalenin mevcut sağlık kurumunda yapılmasının uygun olmadığı durumlarda hekimin her türlü tedbiri alarak hastayı uygun bir merkeze sevk etmesi gerekmekte ve beklenmektedir.

\section{Örnek Olgu 5}

Davacı, "eşinin gebelik takiplerinin ve doğumunun davalı hastanede yine davalı doktor tarafindan yaptırıldığını, dogum sırasında kordonun boyna dolanması nedeniyle bebekte nörolojik sekeller kaldığını, eşinin doğum esnasında hemen sezaryene alınması gerekirken normal doğumda ısrar edildiğini, davalı doktorlar ve hastanenin özen yükümlülüğ̈̈ne aykırı davrandığını" ileri sürerek, fazlaya ilişkin hakları saklı kalmak üzere tazminat talebinde bulunmuş. Davalılar, "sezaryen yapılmasını gerektirir bir bulgunun bulunmadığını" savunarak davanın reddini istemişler. ${ }^{[7]}$

Adli Tıp Kurumu 3. İhtisas Kurulu'ndan alınan 23.03.2011 tarihli raporda, "1980 doğumlu gebenin 24.06.2008 tarihinde davalı hastanede normal vajinal doğum ile 3,250 gr ağırlığında canlı bir bebek doğurduğu, bebeğin yenidoğan asfiksi, yenidoğan solunum sıkıntısı tanısı ile takip edildiği, genel uygulamalarda travayda (doğum eyleminde) olan bir gebenin her 15-20 dakikada bir çocuk kalp sesinin (ÇKS) dinlenmesi gerektiği, en az saatte bir kez NST (non stres test) tetkikinin yapılması gerektiği, tıbbi belgelerin temin edilmediği. . . bebekte meydana gelen rahatsızlığın serebral palsi olarak düşünüldüğ̈̈ göz önüne alındığında, travay takibi ile ilgili belgeler mevcut olmadığından bebeğin intrauterin ne zaman sıkıntıya girdiği, travay takibinin düzgün yapılıp yapılmadığı hususunda görüş bildirilemeyeceği, travay takibi kayıtlarının tutulmamasının bir eksiklik olduğu" mütalaa edilmiştir. ${ }^{7]}$

İtiraz üzerine alınan Adli Tıp Kurumu 2. İhtisas Kurulu'nun 15.03.2013 tarihli raporunda ise; "anne ve bebeğin doğum öncesi düzenli aralıklarla yapılan takiplerinde tıbbi sıkıntı yaşadıklarına dair herhangi bir kayıt olmadığı, bebeğin travay esnasında boynuna dolanan göbek kordonu nedeniyle asfiksiye maruz kaldığı, maruz kalınan asfiksiye bağlı nörolojik sekel kaldı̆̆ı anlaşılmakla, doğumun vajinal şekilde gerçekleştirilmiş olmasına engel herhangi bir tıbbi engelin bulunmayışı, doğum öncesi ve sonrası takiplerin tip kuralları dahilinde gerçekleştirildiği, davalı doktora atfı kabil bir kusur bulunmadığı” mütalaa edilmiştir. ${ }^{[7]}$

Yargıtay, "bebeğin travay esnasında boynuna dolanan göbek kordonu nedeniyle asfiksiye maruz kaldığı sabit olduğuna göre davalı doktorun bu durumun tespiti için gereken takipleri tıp kurallarına uygun olarak yapıp yapmadı ğı, yapılan takip ve kayıtlarda bebeğin ne zaman sıkıntıya girdiği, davacının eşinde sezaryen endikasyonu bulunup bulunmadı̆̆, normal doğum yaptırılmasının tıp kurallarına uygun olup olmadığı, davalı doktor tarafindan uygulanan tedavinin yeterli ve tip kurallarına uygun olup olmadığı hususlarında üniversitelerin ana bilim dallarından seçilecek kadın hastalıkları ve doğum uzmanlarından oluşacak bir bilirkişi kurulundan yeni bir rapor alınması" yönünde karar vermiş ve ilk derece mahkemesi kararını bozmuştur. ${ }^{[7]}$

Serebral palsi hastalığının ortaya çıkması doğum öncesindeki dönemde ya da doğum sırasında kordonun dolanması veya doğumun gecikmesi sonucu asfiksiye bağlı olabilmektedir. Bu süreçlerin de hekimler tarafindan optimum şartlarda yürütülmesi önem teşkil etmektedir.

\section{KAYNAKLAR}

1. T.C. Sağlık Bakanlığı, Tıpta Uzmanlık Kurulu. Ortopedi ve Travmatoloji Uzmanlık Eğitimi Çekirdek Müfredatı v.2.4; 2019. https://tuk.saglik.gov.tr/TR,50120/ortopedi-vetravmatoloji.html

2. T.C. Danıştay Birinci Dairesi. Esas: 2019/1044, Karar: 2019/1070, Tarih: 27.06.2019. https://www.corpus.com.tr/

3. Türk Ceza Kanunu. Kanun Numarası: 5237, Kabul Tarihi: 26/9/2004, Yayımlandığı Resmi Gazete Tarihi: 12/10/2004, Sayısı: 25611, Yayımlandığı Düstur: Tertip: 5, Cilt: 43. https:// mevzuat.gov.tr/

4. T.C. Yargitay 12. Ceza Dairesi. Esas: 2015/9090, Karar: 2016/7867, Tarih: 04.05.2016. https://www.corpus.com.tr/

5. T.C. Yargıtay 13. Hukuk Dairesi. Esas : 2014/26035, Karar: 2015/15290, Tarih: 13.05.2015. https://www.corpus.com.tr/

6. T.C. Yargıtay 13. Hukuk Dairesi. Esas: 2012/7373, Karar: 2013/1944, Tarih: 31.01.2013. https://www.corpus.com.tr/

7. T.C. Yargitay 13. Hukuk Dairesi. Esas: 2014/12357, Karar: 2015/15386, Tarih: 14.05.2015. https://www.corpus.com.tr/ 